\title{
Research on Development of Low Carbon Wollastonite-based Sanitary Products
}

\author{
Wang Xiyuan \\ Donghua University, Shanghai, 20043
}

Keywords: Low-carbon products, low-carbon economy, carbon emissions

\begin{abstract}
Based on the analysis of ceramic sanitary ware products, energy, we put forward a substrate for the energy-saving bathroom wollastonite product development process, and the establishment of a carbon accounting model emissions, carbon emissions were compared to verify the order Wollastonite value of carbon substrate material for the development of low carbon products to establish a theoretical basis.

Since global "low-carbon revolution" rises, the development pattern based on "low energy, low pollution and low emission” challenges the development of high energy-consuming industries. Among numerous high energy-consuming industries, ceramic industry is one of the high energy-consuming industries that are widely depended in life and hard to be replaced.
\end{abstract}

\section{Characteristic analysis on the use and manufacture of sanitary ceramics}

Ceramic is a generic term of the products that are got through molding and firing the natural minerals and synthesized compounds with certain ratio under high temperature ${ }^{[1]}$. Common ceramics, also called traditional ceramics, are obtained through firing natural silicate minerals (such as clay, feldspar and quartz).

Manufacture of the moulds of ceramic products and its influence to the environment. Ceramics production includes three major steps: raw material preparation, billets molding and product firing. Ceramic sanitary wares belong to common ceramics, raw materials of which mainly refer to natural silicate minerals, including clay, quartz and feldspar, and it needs to consume large amount of clay and fuels during production process.

\section{Feasibility analysis on developing alternative wollastonite-based sanitary wares}

Category and characteristics of wollastonite. Wollastonite is a mineral aggregate of calcium metasilicate that generally shows in schistose, radial or fibrous and its major component is calcium metasilicate. It is a kind of common rock-forming mineral and the rocks it forms are not considered to be available minerals. Only when these rocks are used in industrial production, they change from rock to mineral ${ }^{[3]}$.

Research on molding methods of wollastonite-based products. As the molding method of wollastonite-based sanitary wares is totally different from that of ceramic sanitary wares, the difficulties generated during its molding process are also different and the factors that influence its molding are also special to certain extent, which mainly includes two aspects: the influences on molding method itself

Research on design method of the substitutability of wollastonite-based sanitary wares. In existing sanitary wares, for toilet contains complicated functional structures like flush and sewage discharge, as it is shown in Figure 3-2, its structure is the most complicated and its molding process is also much harder than other sanitary wares. In order to research the feasibility for developing substitutability of wollastonite-based products, finding substitute materials for toilet is the most difficult. Therefore, it will mainly analyze the structural characteristics of toilets and then extend to several types of relatively simple sanitary wares.

Research on molding methods of wollastonite-based toilets.

Wollastonite synthetic material is of high whiteness, dielectricity, heat resistance and weather resistance. While combining such material with resin in a certain ratio, a new type of synthetic 
material can be obtained. Experimental results show that the synthesized material could ensure the firmness of product shape with hardness $\geq 6$.

Molding of wollastonite-based sanitary wares also needs moulds. Its moulds used for production should be aluminium alloy or steel. Its molding methods include dry pressing, casting or grouting; and firing is not required during molding process. Its main production flow is shown as Figure 1:

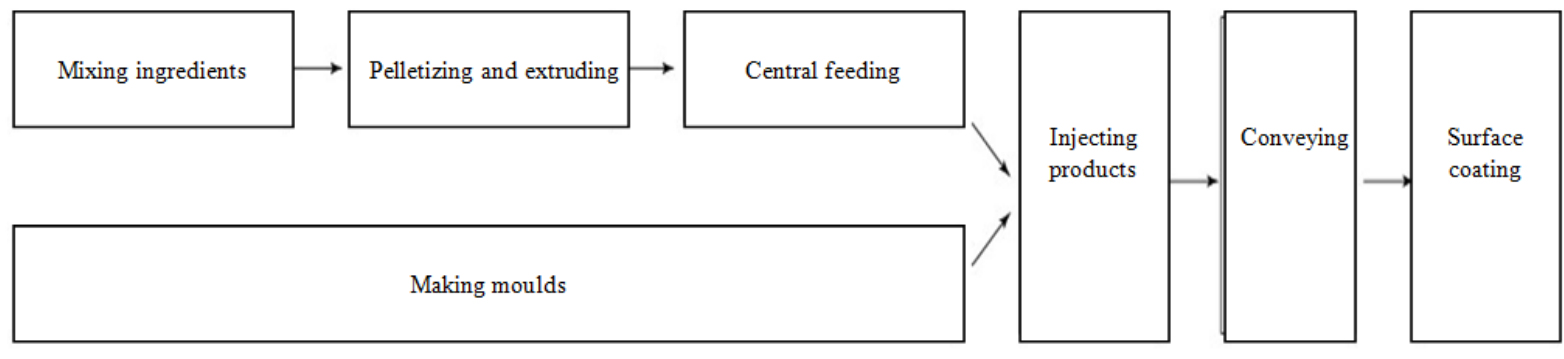

Figure 1 Production Flow of Wollastonite-based Sanitary Wares

(1) Design method of parting modules

For wollastonite-based toilets, mould molding process is adopted to replace firing process of ceramic toilets. Through replacing chemical molding method with physical method, it will reduce the carbon emission generated during firing process and the pollutants generated after ceramic toilet is abandoned that are not easy to be degraded. Molding methods for producing toilets with wollastonite synthetic materials mainly include dry pressing, casting and injection.

(2) Design method of parting module and structure

For the products with complicated structure like toilet, common moulds cannot meet the production requirements. Thus, it needs the mould with parting modules. During production process, cut the designed toilet into several modules and form these modules separately. Design the modules separately; produce different parts of the toilet upon dry pressing, casting or injection; and bond them together after being dried. As the toilet is made through forming parting modules and then assembling and bonding the separate modules together, the product owns the possibility of modularization and transformation processing.

a. Structure parting based on functions

The parting treatment based on functional structure refers that divide the product into several modules according to its functions; and each functional module opens mould and then forms independently. For such parting method, it not only reduces the difficulties of making moulds, but also ensures each functional module to be used normally to the greatest extent. This is the most commonly used parting treatment method in the production of wollastonite-base sanitary wares.

Set toilet as an example. According to its functional characteristics, it could be divided into four modules: siphon structure, toilet body, seat and water tank. This forms a four-module injection production process, as it is shown in Table 1.

Siphon structure refers to inner bedpan of the toilet, which is composed of inner basin and siphon bends. The first module could be completed with half mould.

Toilet body is the second module that refers to the outer body which covers siphon structure. It could protect siphon structure and it allows different styles according to its shape.

Seat refers to the top edge of toilet body that contacts human body. It connects the inner basin of siphon structure and outer body of the toilet; and it leads water to flush the inner basin. Design of the seat is significant. Embed water manifold in this seat to connect to water tank, so as to flush the wall of inner basin; and then connect outer body and siphon inner basin with snap fitting structure. Seat is the third module.

As the common connector that connects toilet body, siphon structure and seat, water tank is the forth module. And it could be cast into different shapes.

b. Structure parting based on processes

The parting treatment based on molding process is on the basis of functional structure. For the functional structure with simple shape, it should be formed upon dry pressing; while for the 
functional structure with complicated shape, it should be formed upon casting or injection.

During dry pressing of wollastonite-based sanitary wares, simple mould should be adopted for mould design. Still set the toilet in Table 1 as an example. This product has been divided into four modules: siphon structure, toilet body, seat and water tank. Secondary parting could be made on these four modules according to their shapes. After secondary parting, the simple parts could be formed upon dry pressing and the complicated parts could be formed through casting or injection.

Siphon structure is composed of inner basin and siphon bend. As shape of the siphon bend is very complicated, if any error happens during its molding process, it will directly influence sewage capacity of the toilet. Thus, siphon bend could be produced uniformly as a standard component of the product. And as the inner basin influences little on sewage capacity, shape of inner basin could change a little according to outer appearance. But it needs to ensure interface shape of inner basin and that of siphon bend to be consistent; or else, it may influence sewage capacity, as it is shown in Table 2.

Table 1 Requirements to the Case about Toilet Design upon Injection

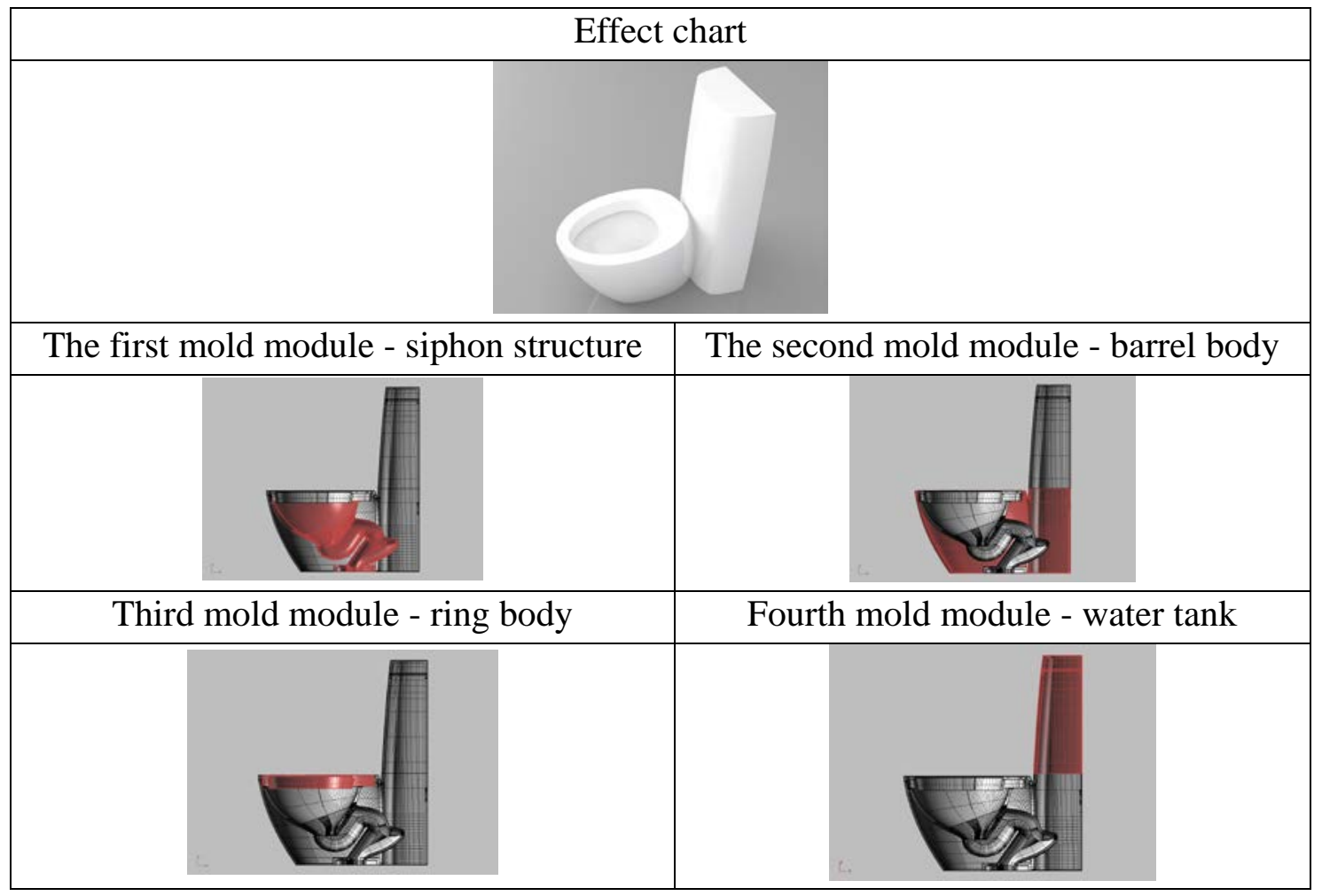

Table 2 Requirements to the Case about Siphon Structure Molding

\begin{tabular}{|l|l|}
\hline The first mold module - the bowl & The second mold module - siphon trap \\
\hline
\end{tabular}


Shape of the seat is relatively simple and it is mainly designed to be demoulded for once to twice. Set the toilet seat in Table 1 as an example and it could finish demoulding for once upon dry pressing. In order to ensure both parts of demoulding to succeed, it needs to design the technical indexes related to demoulding angle of the product.

According to the flush structure of ceramic toilet, the seat acts as part of the pipeline. Some flush gaps are designed to be distributed under the seat and molding of these gaps is difficult for the molding process of wollastonite-based toilet, and it needs a method that is completely different from the molding method of ceramic toilet to solve this problem. According to experiments, it could make pipeline function of the entire structure available through embedding pipelines, then flush gaps are set on the pipeline and after they are formed separated, bond them together.

Water tank is composed of two parts: cap and body. Molding method of each separate part is basically the same with that of the seat. It needs to be noted that as water tank is composed of the cap and body and as the body takes a large volume, while molding upon dry pressing, the volume of its mould is also larger than seat and cap. But as it doesn't need to be dried during dry pressing, it is of a certain advantages compared with casing and injection. Set water tank of the toilet in Table 1 as an example. The cap and body could be designed to be formed separately upon dry pressing. But it needs to design demoulding angle, wall thickness and other indexes related to water tank.

For forming the tank body in the above table, as the bottom is larger than the mouth for the water tank in this case, one-time molding is not suitable here. It could form the curved surface (front and side) and plane (back) separately, and then bond them together. From this point, if trying to avoid such mould while considering mould opening method during design, it could avoid parting and bonding for many times, which greatly reduces the workload of mould opening and molding process.

Surface structure processing.

Surface coating technology of wollastonite-based sanitary wares has been improved and UV coating is often used to paint the surface. UV coating could dry fast under the action of ultraviolet photons. During the process that UV coating forms a film, namely it changes from liquid to solid, there is no or basically no solvents that volatilizes, so that it could realize zero emission or low emission of volatile organic compounds $(\mathrm{VOC})^{[4]}$. UV coating also owns the advantages including high brightness, big surface strength, strong pollution resistance, self-cleaning, etc.

Titanium dioxide $\left(\mathrm{TiO}_{2}\right)$ photocatalyst technology could be adopted at the same time. Experimental results show that within certain area and time, $\mathrm{TiO}_{2}$ could reduce over $18 \%$ of mildews in the air. After absorbing the ultraviolet in sunlight or lighting source, $\mathrm{TiO}_{2}$ will generate a group of positive and negative charges and electrons; charges are able to oxidize and electrons are able to reduce; after reacting with water, it will generate hydroxyl radical $\left(\mathrm{OH}^{-}\right)$, which will decompose viruses and dust mites that do harm to human beings as well as the organic substances that smell odd, so as to greatly slow down dirt accumulation ${ }^{[5]}$.

\section{Comparison between carbon emissions of wollastonite toilet and ceramic toilet}

Calculate the carbon emission generated during the entire wollastonite-based toilet production process. Carbon emission during the entire wollastonite-based toilet production process includes two parts: mould production and product production. Carbon emission refers to the amount of carbon dioxide $\left(\mathrm{CO}_{2}\right)$ generated while people consuming fossil fuels (coal, petroleum, natural gas). The amount of $\mathrm{CO}_{2}$ generated while burning fossil fuels could be calculated with the method proposed by ORNL (Oak Ridge National Laboratory):

\section{Coal-fired carbon emission=coal consumption $\times 0.982 \times 0.73257$}

(In this equation: “0.982” represents effective oxidation fraction; “0.73257” represents carbon content of 1 t standard coal)

Calculate the carbon emission generated during steel moulds making process.

While using wollastonite synthetic materials to produce toilets, parting-module mould opening method is adopted; molding methods mainly include dry pressing, casting and injection; and the 
main material used to make moulds is steel. While making moulds, the steel needs to be smelted into liquid first. At the present stage, the smelting unit mainly used in Chinese plants is induction smelting furnace. During smelting, power consumption per unit steel is $600-700 \mathrm{~kW} \cdot \mathrm{h} / \mathrm{t}$.

Calculate the carbon emission generated during casting and injection process.

To the society's demand for explaining carbon footprint, project party entrusts SGS (short for Societe Generale de Surveillance S.A.) to calculate the carbon footprint of a nonmetallic composite toilet made as building materials of sanitary ware in trial production without accessories, so as to know about greenhouse gas emission (GGE) of existing products during production cycle.

Project party provides a 43kg wollastonite-based toilet (excluding accessories) with product model Z2010-01, packed by corrugated paper. Upon test, it could calculate that GGE of the materials of single toilet takes up over 53\% of total emission, including $45.44 \%$ for raw materials, $3.04 \%$ for consumables and $4.86 \%$ for packing materials. And the carbon emission generated during product manufacturing process exceeds $40 \%$ of total emission, as it is shown in Table3

Table 3 Detailed Catalogue for the GGE Generated during Life Cycle of Single Toilet

\begin{tabular}{|c|c|c|}
\hline Specific item & $\mathrm{kg} \mathrm{CO}_{2} \mathrm{e}$ & Percentage \\
\hline $\begin{array}{c}\text { Materials } \\
\text { (raw materials, product packing } \\
\text { materials and consumables) }\end{array}$ & 38.6687 & $55.34 \%$ \\
\hline Package of materials & 2.1513 & $2.97 \%$ \\
\hline Transportation of materials & 1.8539 & $2.56 \%$ \\
\hline Product manufacturing process & 29.1589 & $40.22 \%$ \\
\hline Waste disposal & 0.6568 & $0.91 \%$ \\
\hline Total & 72.4896 & -- \\
\hline
\end{tabular}

Upon experimental calculation, it could be concluded that for a 43kg wollastonite-based toilet without accessories, its carbon emission for raw materials preparation, product manufacturing and waste disposal during life cycle is $72.4896 \mathrm{~kg}$, which could be converted to about $0.0725 \mathrm{t}$.

Calculate the carbon emission generated during the entire ceramic toilet production process. Carbon emission during the entire ceramic toilet production process also should include mould production and product production. Thus, it needs to calculate the carbon emission for the entire process and it is real and effective after comparing with wollastonite-based toilet.

Calculate the carbon emission generated during plaster moulds making process.

Making moulds for ceramic toilets seems to cost little, but actually high consumption and high pollution. Set the toilet in Table 1 as an example. It needs $0.286 \mathrm{t}$ plaster of paris. While making moulds, it needs heating. Generally, fluidized bed is needed to prepare calcium sulfate hemihydrate. Thus, the heating process consumes electric power and using coal to generate electric power will generate carbon emission.

Calculate the carbon emission generated during molding process.

In the carbon footprint mid-term calculation report of the above product, SGS has analyzed the energy consumption for the production process of common ceramic toilet that is equal in mass. Energy consumption for the production process of common ceramic toilets includes six processes: raw materials production, material preparation, molding, enamel frit making, firing and refiring. During raw materials production, it needs four means of production, including coarse jaw crusher, intermediate edge runner, ball grinder and glaze ball grinder. During this process, energy consumption of unit raw materials is $406.8 \mathrm{~W}$ in total,

Material preparation includes mixing and casting. Hereinto, during mixing process, energy consumption for $1 \mathrm{~kg}$ raw materials can be calculated as: 
$(100 \mathrm{~kW} \times 8 \mathrm{~h} \times 300 \mathrm{D}) \div 5616 \mathrm{t}=0.04274 \mathrm{~kW}=42.74 \mathrm{~W}$ (in this equation, "100kW" represents power of the means of production, "8h" represents working hours per day, “300D” represents workdays per year and " $5,616 \mathrm{t}$ " represents annual output of common ceramics); during casting process, energy consumption for $1 \mathrm{~kg}$ raw materials can be calculated as: $(73.25 \mathrm{~kW} \times 8 \mathrm{~h} \times 300 \mathrm{D}) \div 5616 \mathrm{t}=0.0313 \mathrm{~kW}=31.3 \mathrm{~W}$ (in this equation, “73.25kW” represents power of the means of production and others are the same with the above equation). Then, energy consumption of unit raw materials during material preparation is $74.04 \mathrm{~W}$ in total.

During toilet molding process, it includes power consumption and diesel consumption. Hereinto, power consumption for $1 \mathrm{~kg}$ raw materials can be calculated as: $(31.5 \mathrm{~kW} \times 8 \mathrm{~h} \times 300 \mathrm{D}) \div 5616 \mathrm{t}=0.01346 \mathrm{~kW}=13.46 \mathrm{~W}$ (in this equation, “31.5kW" represents power of the means of production and others are the same with the above equation); diesel consumption for $1 \mathrm{~kg}$ raw materials can be calculated as: $480 \mathrm{t} \div 5616 \mathrm{t} \div 1000=0.08547 \mathrm{~kg}=85.47 \mathrm{~g}$ (in this equation, “480t” represents diesel consumption of molding process during the whole year, " $5,616 \mathrm{t}$ ” represents annual output of common ceramics and “ $1,000 t$ ” represents conversion fraction from ' $\mathrm{t}$ ' to ' $\mathrm{kg}$ ').

During enamel frit making process, it only consumes electric power. During this process, power consumption for $1 \mathrm{~kg}$ raw materials can be calculated as: $(72.1 \mathrm{~kW} \times 16 \mathrm{~h} \times 350 \mathrm{D}) \div 5616 \mathrm{t}=0.07189 \mathrm{~kW}=71.89 \mathrm{~W}$ (in this equation, “72.1kW” represents power of the means of production, " 16 h" represents working hours per day, "350D” represents workdays per year and " $5,616 \mathrm{t}$ ” represents annual output of common ceramics).

During toilet firing process, it consumes electric power and diesel. Hereinto, power consumption for $1 \mathrm{~kg}$ raw materials can be calculated as: $(142 \mathrm{~kW} \times 24 \mathrm{~h} \times 360 \mathrm{D}) \div 5616 \mathrm{t}=0.21846 \mathrm{~kW}=218.46 \mathrm{~W}$ (in this equation, " $142 \mathrm{~kW}$ " represents power of the means of production, "24h" represents working hours per day, "360D” represents workdays per year and "5,616t" represents annual output of common ceramics); diesel consumption for $1 \mathrm{~kg}$ raw materials can be calculated as: $866.7 \mathrm{t} \div 5616 \mathrm{t} \div 1000=0.1543 \mathrm{~kg}=154.3 \mathrm{~g}$ (in this equation, " $866.7 \mathrm{t}$ " represents diesel consumption of firing process during the whole year, " $5,616 \mathrm{t}$ " represents annual output of common ceramics and " $1,000 \mathrm{t}$ ” represents conversion fraction from ' $\mathrm{t}$ ' to ' $\mathrm{kg}$ ').

During refiring, it only consumes diesel. During this process, diesel consumption for $1 \mathrm{~kg}$ raw materials can be calculated as: $108 \mathrm{t} \div 5616 \mathrm{t} \div 1000=0.01923 \mathrm{~kg}=19.23 \mathrm{~g}$ (in this equation, "108t" represents diesel consumption of firing process during the whole year, "5,616t" represents annual output of common ceramics and " $1,000 \mathrm{t}$ ” represents conversion fraction from ' $\mathrm{t}$ ' to ' $\mathrm{kg}$ ').

To sum up, it consumes $784.65 \mathrm{~W}$ electric power and $259 \mathrm{~g}$ diesel to produce $1 \mathrm{~kg}$ common ceramics. SGS coverts total diesel consumption to power consumption of $1,227 \mathrm{~W}$ and then power consumption for $1 \mathrm{~kg}$ product is $2,012 \mathrm{~W}$ in total. Calculating pass rate of finished product as $60 \%$, then the power consumption for $1 \mathrm{~kg}$ product is $3.35 \mathrm{~kW}$ and carbon emission for producing $1 \mathrm{~kg}$ product is $5.025 \mathrm{~kg}$. For the above $43 \mathrm{~kg}$ toilet, carbon emission can be calculated as: $43 \mathrm{~kg} \times 5.025=216.075 \mathrm{~kg}$, which can be converted to $0.2161 \mathrm{t}$.

Carbon emission comparison and carbon tax conversion analysis of product production. Through analyzing specific molding methods of wollastonite-based sanitary wares, it has proved the feasibility about replacing ceramic materials with wollastonite to produce sanitary wares from molding structure. It compares the carbon emissions generated while producing products with these two types of materials and proves the possibility of using wollastonite to replace ceramics from economic development.

Carbon emission comparison and carbon tax conversion analysis of product production.

Some European and American developing countries have started to collect taxes for carbon dioxide emission since several years ago. It's known that current carbon tax in Europe is RMB 200-300/t.

As product shapes are different, masses of the materials used to produce different types of toilets are also different. Thus, it needs to propose a formula to calculate the carbon emission of unit mass product, so as to make carbon tax comparison. It could be concluded upon calculation that carbon emission for smelting $1 \mathrm{t}$ steel is $0.1685 \mathrm{t}$ and then it can be expressed as: carbon emission during steel smelting $=$ total mass of steel $\times 0.1685$ (unit: $t$ ). According to the data provided in the 
carbon footprint mid-term calculation report for wollastonite-based toilets issued by SGS, the carbon emission of a $43 \mathrm{~kg}$ wollastonite-based toilet is equal to $72.49 \mathrm{~kg} \mathrm{CO}_{2}$, then it could figure out that while producing $1 \mathrm{t}$ wollastonite-based product, it generates $1.6858 \mathrm{t}$ carbon emission. Then it can be concluded that: carbon emission during wollastonite product production $=$ total mass of wollastonite $\times 1.6858$ (unit: t).

It's known that it consumes $4,798 \mathrm{~kW} \cdot \mathrm{h}$ electric power to prepare $1.5 \mathrm{t}$ calcium sulfate hemihydrate and upon the data provided by NDRC, it could figure out that the coal consumption for preparing $1.5 \mathrm{t}$ calcium sulfate hemihydrate is about $1.59933 \mathrm{t}(=4798 \div 3000 \approx 1.59933 \mathrm{t})$. It could be concluded through calculating the formula proposed by ORNL that the carbon emission for preparing 1t water-free calcium sulfate is $1.1505 t$, then it can be expressed as: carbon emission for preparing calcium sulfate hemihydrate $=$ total mass of calcium sulfate hemihydrate required by moulds $\times 1.1505$ (unit: t). Similarly, SGS also has offered that the carbon emission for producing the common ceramic toilets of the same mass is equal to $216.075 \mathrm{~kg} \mathrm{CO}_{2}$, then the carbon emission for producing $1 \mathrm{t}$ common ceramic products is $5.025 \mathrm{t}$. Then, it could be expressed as: carbon emission generated during production process of common ceramic products $=$ total mass of common ceramic products $\times 5.025$ (unit: t).

According to the above calculation, it could get the carbon emission for unit mass product and unit mass mould. The specific numerical values and carbon taxes are shown in Table 4.

Table 4 Carbon Emission Comparison and Carbon Tax Calculation for the Toilets Produced by Traditional Materials and Wollastonite Synthetic Materials

\begin{tabular}{|c|c|c|c|c|}
\hline \multirow{2}{*}{} & \multicolumn{2}{|c|}{ Wollastonite-based products } & \multicolumn{2}{c|}{ Common ceramic products } \\
\cline { 2 - 5 } & $\begin{array}{c}\text { Carbon } \\
\text { emission }\end{array}$ & $\begin{array}{c}\text { Carbon tax } \\
\text { (RMB 40/t) }\end{array}$ & $\begin{array}{c}\text { Carbon } \\
\text { emission }\end{array}$ & $\begin{array}{c}\text { Carbon tax } \\
\text { (RMB 40/t) }\end{array}$ \\
\hline $\begin{array}{c}\text { Unit mass } \\
\text { mould }\end{array}$ & $0.1685 t$ & RMB 6.74 & $1.1505 t$ & RMB 46.02 \\
\hline $\begin{array}{c}\text { Unit mass } \\
\text { product }\end{array}$ & $1.6858 \mathrm{t}$ & RMB 67.432 & $5.025 \mathrm{t}$ & RMB 201 \\
\hline
\end{tabular}

To sum up, the following two equations can be obtained:

(1) During the entire production process, carbon emission of single wollastonite product and payable carbon tax could be calculated with:

$$
\begin{aligned}
E_{\text {carbon }} & =\frac{0.1685 \times Q_{\text {model }}}{10000}+1.6858 \times Q_{\text {product }} \\
T_{\text {tax }} & =\frac{6.74 \times Q_{\text {model }}}{10000}+67.432 \times Q_{\text {product }}
\end{aligned}
$$

Hereinto, $E_{\text {carbon }}$ represents the carbon emission $(\mathrm{t})$ during the entire single wollastonite product production process; $T_{\text {tax }}$ represents the payable carbon tax (RMB) during the entire single wollastonite product production process; $Q_{\operatorname{model}}$ represents total mass of the steel used to make moulds; $Q_{\text {product }}$ represents total mass of the wollastonite used to produce the product; take service life of each mould as 10,000 times; and take carbon tax as RMB 40/t.

(2) During the entire production process, carbon emission of single common ceramic product and payable carbon tax could be calculated with:

$$
E_{\text {carbon }}^{\prime}=\frac{1.1505 \times Q^{\prime}{ }_{\text {model }}}{80}+5.025 \times Q^{\prime}{ }_{\text {product }}
$$




$$
T_{\text {tax }}^{\prime}=\frac{46.02 \times Q_{\text {model }}^{\prime}}{80}+201 \times Q_{\text {product }}^{\prime}
$$

Hereinto, $E^{\prime}{ }_{\text {carbon }}$ represents the carbon emission (t) during the entire single common ceramic product production process; ${ }^{T}{ }_{\text {tax }}$ represents the payable carbon tax (RMB) during the entire single common ceramic product production process; $Q^{\prime}{ }_{\text {model }}$ represents total mass of the plaster used to make moulds; $Q^{\prime}{ }_{\text {product }}$ represents total mass of the ceramic raw materials used to produce the product; take maximum service life of each mould as 80 times; and take carbon tax as RMB 40/t.

\section{Conclusion}

Through calculating the carbon emissions generated while producing toilet with wollastonite and ceramics and also taking in carbon tax to make comparison, the results indicate that compared with ceramic sanitary wares, the wollastonite sanitary wares own obvious advantages in carbon emission. The formulas used to calculate carbon emissions and carbon taxes generated while producing with these two materials are offered to provide convenient to later production and promotion. As an emerging industry that meets the development demand of low-carbon economic development, production and promotion of wollastonite-based sanitary wares enter into people's life, which makes for promoting to solve the global issue of environmental protection and its active influence on our economic construction also cannot be underestimated.

\section{References}

[1] Jiang Xiangyun. Design Materials and Processing Technologies [M]. Beijing: Beijing Institute of Technology Press, 2010: 117.

[3] Sun Mingfei. Best Way to Find Mineral Deposit [C]. Beijing: Geological Publishing House, 1986: 66.

[4] LV Yanxiao. UV Coating and Radiation Curing (Volume I) [N]. China Chemical Industry News, 2005-3-29 (6).

[5] Liang Feng. Green Building Materials - Characteristics of Silicon Fiber Ceramic Plate and Application of New Technologies [J]. Shanghai Construction Science \& Technology, 2006 (4): 60-61. 